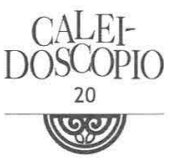

JULIO-DICIEMBRE 2006

\title{
La disolución de la primera persona en P. Ricoeur
}

CALEB OLVERA ROMERO $1 /$ UAZ

Yo, una ficción de la que asumo somos

coautores.

Imre Kertész

Sólo poseo una identidad, la identidad

de escribir

una identidad que se escribe a sí misma.

Imre Kertész

\begin{abstract}
Con el título de Soi-même comme un autre, Ricoeur ha querido reunir tres tradiciones filosóficas que hacen converger y forman el corpus del presente texto. La primera de ellas es la fenomenología en la que se ha formado, ${ }^{2}$ y que ha puesto la pauta para una crítica al ego cartesiano, desde la perspectiva de una epoje. ${ }^{3}$ Esta tradición, ha dado varios libros sobre la misma temática, el ego. En Sí mismo como otro, ${ }^{4}$ P. Ricoeur
\end{abstract}

1 C. a Dr. Por la Universidad Autónoma de Zacatecas, UAZ, profesor investigador en la misma institución dentro del programa de Maestría en Filosofía.

2 Ver T. Italo Calvo, P. Ricoeur, Los caminos de la interpretación, Ed. Anthropos, Barcelona, 1991.

3 Edmundo Husserl, E., Conferencias de París, Ed. UNAM, México 1988, pág. 34.

4 Paul Ricoeur,, Sí mismo como otro, Ed. Siglo XXI, México, 1996. 
aborda directamente el tema de la persona de la misma manera en que antaño lo hiciera Edith Stein, en su libro Sobre el problema de la empatía, ${ }^{5}$ aunque con una carga teórica diferente. En ambos libros se trata principalmente la cuestión de la primera persona. Aunado a esto y también formado en la fenomenología se encuentra el libro de J. P. Sartre, La trascendencia del ego, ${ }^{6}$ que no es sino otro argumento directo en pro de afinar la tradición cartesiana, desde la fenomenológica. De alguna manera Ser y tiempo también desarrolla la temática. No obstante, aunque todos ellos estén formados en la misma tradición y traten el mismo problema, los resultados parecen incluso opuestos o por lo menos diametralmente distintos.

Predecesor de estos libros es sin duda, Las meditaciones cartesianas ${ }^{7}$ del mismo Husserl, que por el principio del siglo pasado se ocupaba con principal devoción de la temática de un ego fenomenológico. Aunque formado en la fenomenología, Ricoeur se apoya más en Heidegger en contra del maestro, $y$ adquiere de él la licencia para pensar el ser sin rodeos. ${ }^{8}$ El autor de Ser y tiempo, plantea el Dasein como un ser temporal e histórico, ${ }^{9}$ y no es otra cosa, sino esta simple idea la que va a desarrollar hasta sus últimas consecuencias nuestro autor. Así la segunda tradición que confluye en su obra es la hermenéutica. Un pensamiento que pretende contextualizar para obtener el sentido enriquecido de la obra, pero que no se limita a contextualizar el texto sino a hacer de nosotros un texto. En La metáfora viva ${ }^{10}$ ya se encuentran las líneas de este planteamiento, sin embargo nos hará esperar un par de décadas para poner frente a la mesa el fruto de esta reflexión; Sí mismo como otro no

5 Edith Stein, Sobre el problema de la empatía, Ed. Trotta, Madrid 2004.

6 Jean Paul Sartre, La trascendencia del ego, Ed. Calden, Buenos Aires 1998.

7 Edmundo Husserl, E., Meditaciones cartesianas, Ed. FCE, México 2005.

8 Mauricio Beuchot nos dice que Ricoeur llama a la postura de Heidegger una ontología de la comprensión. Que ya no está encerrada en el yo, en la subjetividad, y se puede pensar en pasar al mundo con todo derecho. M. Beuchot, Hermenéutica, lenguaje e inconsciente, Ed. AAP, México, 1989, pág. 17.

9 Martín Heidegger, Ser y tiempo, Ed. FCE, México, 1980, pág. 53 y ss.

10 Ahí encontramos el germen de todo el planteamiento ulterior, pues se observa que en su búsqueda de la semejanza, ésta debe entenderse como una tensión entre la identidad y la diferencia. Paul Ricoeur, La metáfora viva, Ed. Trotta, Madrid, 2001, pág. 12. 
es más que la idea de un hombre metáfora, (un hombre analógico, guiño a Beuchot) interpretado hermenéuticamente. La idea gadameriana de la lingüisticidad y el horizonte, son fusionados en una misma idea interpretativa, el hombre es lingüisticidad y horizonte. Horizonte histórico que en Verdad y método se emparienta con la "tradición"11 y que ya en ser y tiempo, se proponía como historicidad. La idea central del círculo hermenéutico, es la refundación de la esencia del autor y del texto en una relectura, ${ }^{12}$ del mismo modo en que un sujeto puede refundar su esencia si se vuelve a interpretar. Así se vuelve a presentar la idea de hacer del yo un tú o mejor aún, partiendo de la propuesta de Levinas, es hacer del "tú" un "yo", algo sujeto a un horizonte y a una tradición, algo sujeto a ser interpretado desde otro sujeto, ambos son sujetos, o como nos diría Levinas; somos rehenes de los Otros, pues El esse humano no es, primordialmente conatus sino rehén, rehén de los demás..$^{13}$ Sin embargo, este otro es rehén mío y así el círculo hermenéutico queda fundado, ya no sobre el texto y la interpretación sino sobre el sujeto y lo que lo sujeta, el Otro, y la lingüisticidad que ahora les ha dado horizonte.

Así tenemos hasta ahora dos tradiciones, la fenomenológica y la hermenéutica, pero esto no basta, pues quien ha tratado el tema con mayor intensidad, es la tradición analítica. Así la línea que nuestro autor va a seguir es la analítica pero, poco a poco la hace concluir en la hermenéutica. Ryle, ${ }^{14}$ Strawson,,${ }^{15}$ Wittgenstein, ${ }^{16}$ Parfit, ${ }^{17}$ son el eje

11 Hans Georg Gadamer, Verdad y método, Ed. Sígueme, Salamanca, 1977, pág. 225 y ss.

12 Esta simple idea resulta revolucionaria, pues taja la tradición metafísica al hacer de la esencia algo dependiente de la lectura, hace de la esencia una relación entre lector y lectura entre creador y obra. Ver Martín Heidegger, Arte y poesía, Ed. Fce, México, 1980.

13 Emanuel Levinas, Dios, la muerte y el tiempo, Ed. Cátedra, Madrid 1994, pág. 33.

14 La crítica más elaborada teóricamente en contra del ego cartesiano, la encontramos en G. Ryle en su libro, El concepto de lo mental, Ed. Paidos, Barcelona 2005. Es un claro ejemplo de lo que constituirá las directrices de la crítica contra Descartes por parte de los analíticos. Aunque se desprenden de ésta, por considerarla de índole conductista. Es la obra que traza un poco el camino de Sí mismo como otro.

15 De este autor toma como punto de referencia los particulares de base, y sobre todo la noción de una construcción corporal a través de la posición orgánica del campo visual. Strawson, P. F., Individuos, Ed. Taurus, Madrid, 1989, pág. 90 y ss. 
que marca como un faro, el inicio de la problemática. A pesar de esto, la posición ha sido tomada desde mucho antes, y aunque conoce las críticas a Descartes por parte de Russell, Taylor y Putnam, el punto neural desde donde despliega la suya, lo constituye la crítica de Hume y Locke. El primero incidía en que Nada sujeto al tiempo posee una identidad en sí mismo pues para él la identidad que atribuimos a la mente humana es tan sólo ficticia. ${ }^{18}$ Por ello nada es idéntico a sí mismo, obsérvese la semejanza del planteamiento humano con la propuesta desarrollada por P. Ricoeur. Con la falta de una identidad, Hume necesariamente tiene que solucionar la cuestión de la identificación, cómo es que reconozco a alguien como el mismo que he visto hace dos o diez años, y plantea, congruente con su desarrollo y de frente a la crítica tradicional de la potencia y la sustancia, una identidad imperfecta. La identidad imperfecta es, aunque no lo dice Hume, más que nada una identificación. Así resaltemos solamente una idea del inglés, y dejemos en claro que existen dos tipos de identidades: perfectas e imperfectas, las perfectas sólo se dan en aquello no sujeto al tiempo, como son los números y algunos otros conceptos; todo lo demás sujeto al tiempo tiene una identidad imperfecta, alias identificación. Con Locke pasa algo distinto ${ }^{19}$, para él la cuestión de la identidad se resuelve en un tercero que nos identifica como los mismos, así el problema no es la identidad sino el sí mismo, "sí mismo" que interesa directamente a P. Ricoeur para desarrollar su teoría. Ya desde Tiempo y narración la cuestión de la identificación es la base fundamental de la teoría de la identidad del personaje.

16. Del austriaco va a recoger toda la influencia en contra de la utilización sustancial de los objetivos y cómo es que esta confusión crea entes de una existencia conflictiva, como lo son el alma, el sujeto y el yo. Ver Wittgenstein, L., Los cuadernos azul y marrón, Ed. Planeta Agostini, Barcelona, 1994.

17 La obra Razón y personas de Derek Parfit es la crítica central pues es la que conflictúa más directamente las propuestas de una identidad ipse. Ver D. Parfit, Razón y personas Ed, Visor, 2000.

18 David Hume, Tratado de la naturaleza humana, Ed. Tecnos, Madrid, 1988, pág. 365.

19 Véase John Locke, Ensayo sobre el entendimiento humano, Ed. Gernika, México, 1988. 


\title{
LA IMPLICACIÓN DE LA IPSEIDAD
}

P. Ricoeur nos dice que existe una primacía de la mediación reflexiva sobre la posición inmediata del sujeto, tal como se expresa en la primera persona del singular: "yo pienso", "yo soy". ${ }^{20}$ Las lenguas naturales apoyan una distinción entre "sí mismo" y "yo" pues el pronombre personal indicativo de la primera persona, apoya una sustancialización hablante ya auto reflexiva, mientras que "sí mismo", indica más un acto locutivo de identificación.

El "sí" se define en principio como un pronombre reflexivo... No obstante esto desaparece si se relaciona el término "Sí" con el término "se", refiriendo a su vez, a verbos en modo infinitivo; se dice: "presentarse", "llamarse", etc. ${ }^{21}$ Estos usos, como nos sugiere nuestro autor basándose en la lectura de G. Guillaume, adquieren su plenitud en el infinitivo. Este es quizá el punto neural de la crítica de Levinas hacia su maestro Heidegger, pues para él, el Dasein no es un ser ahí, sino un "siendo" y esto, según su alumno, es realmente meter al ser abyecto dentro de su condición temporal. Pero nuestro autor no se queda ahí, en el análisis de los infinitivos, sino que agrega que es incluso en el participio donde la distribución del "se" en los tiempos verbales y las personas gramaticales, adquiere una mayor riqueza y es ahí donde:

\begin{abstract}
el "se" designa entonces el reflexivo de todos los pronombres personales, incluso de los pronombres y locuciones impersonales, tales como "cada uno", "cualquiera que", "uno" a los cuales se alude frecuentemente en el curso de las investigaciones. Esta disgresión en torno al "se"no es superflua ya que el propio pronombre reflexivo "sí" accede a la misma amplitud cuando completa el "se" asociando al modo infinitivo: Designarse a sí mismo. ${ }^{22}$
\end{abstract}

Con esta relativización y ampliación del pronombre en relación al "se" logra la fórmula que dará horizonte a dos pensamientos; por un lado la

\footnotetext{
20 Paul Ricoeur, Sí mismo como otro, Ed. Siglo XXI, México, 1996, pág XI.

21 Ibid.

22 Ibid.
} 
hermenéutica del "sí" que desarrolla Foucault, ${ }^{23}$ y por otro, la temática del auto nombrarse y fundirse en este "nombrarse". Con este autonombrarse nuestro autor invoca a la tradición recordando la Ilialidad de quien nombra y en este acto crea a sí mismo, Ili. Quien dice soy el que soy. Así la autodenominación funda no solamente los cuidados del "sí" sino la identidad del que nombra y de quien responde a su llamado. ¿Quién eres? soy el que soy, soy el que nombra. Lo importante está en esa forma gramatical que relativiza al pronombre reflexivo "sí" del "sí mismo" con el "se", del "designarse" se abre así la vena gramatical del autocomprenderse, designándose, "Quién soy" palabra enriquecida pues es llevada a la ontología fundante, no sólo del mundo como en su momento lo hace Heidegger sino del Ser ahí, la palabra no solamente es la matriz del mundo sino de nosotros mismos. Ahora bien, conviene observar que este giro nada tiene de extraño, en la medida en que los nombres mismos que admiten el "sí" en un caso indirecto son infinitivos nominalizados, como atestigua la equivalencia de las expresiones: "preocupación de sí mismo" y "cuidado de sí", 24 bajo la licencia del desliz nominativo Ricoeur pretende nominalizarlo todo y juega con las expresiones "el beber" "el hermoso presente" y llega al ejemplo que quería, al nominalizar el "sí" y obtener "el sí". No se detiene en este punto, pues la mira está puesta un paso más allá, y alinea bajo esta misma licencia las formas gramaticales que son usadas como pronombres personales, en una posición del sujeto gramatical emitiendo un acto locutivo, y así obtiene "el yo" y se extiende para plantear "el tú" y "el nosotros" Finalmente nos dice:

Esta nominalización, menos tolerada en las lenguas románticas que en el alemán o en el inglés, solo resulta abusiva si se olvida la filiación gramatical a partir del caso indirecto consignado en la expresión: "designación de sí" derivada a su vez, por primera nominalización, del infinitivo reflexivo: "designarse a sí mismo"25 y esta es la expresión que va a adquirir para el resto de su obra.

23 En 1980, Michel Foucault dicta una serie de conferencias en la Universidad de Berkeley, que con algunas variables deberían de ser el último tomo de Historia de la sexualidad, Ed. Siglo XXI, México, 1991. Estas conferencias, según sugirió, deberían de compilarse bajo el título de Acerca del comienzo de la hermenéutica del yo. Véase OrtizOses, Diccionario de hermenéutica, pág. 759.

24 Id. pág. XII.

25. Ibid. 
El planteamiento anterior es obligado si queremos, como lo hace nuestro autor, plantear la distinción de "el sí mismo" con sus dos significados importantes de identidad. Por identidad se puede entender el ídem y el ipse. Y sostiene que el "sí" del "sí mismo" contrae una ambigüedad en cuanto a la noción de identidad. La identidad ídem, contrae las mismas problemáticas que esgrimía Hume en contra de la identidad perfecta. Así, la tesis fundamental de nuestro autor que ya se venía dibujando desde Tiempo y narración ${ }^{26}$ y El discurso de la acción ${ }^{27}$ es que: la identidad en el sentido de ipse no implica ninguna afirmación sobre un pretendido núcleo no cambiante de la personalidad. ${ }^{28}$ Con esta simple línea, la disolución del sujeto entendido como sustancia ha sido realizada y. se perfila la crítica contra la tradición denominada Ghost in the Machine. Ahora nos enfrentamos con un sujeto idéntico a "sí mismo" sólo en la medida en que este "sí mismo", no contenga implicaciones de afirmaciones de un núcleo no cambiante; con esto se plantea su crítica en contra de la tradición, no solamente de la esencia sino de la sustancia, representadas por Aristóteles y Descartes quienes son el blanco del ataque. El fantasma dentro de la máquina, etiqueta con la cual se designa la tradición que cree en un yo como sustancial y esencial, es diluida en nombre de una relativización de "sí" en la forma gramatical del autonombrarse, es decir del "se".

Congruente con su trabajo ético, le interesa rescatar una identidad de responsabilidad, una identidad que no arrastre tras su disolución a la ética, ni a la política. La identidad que nos propone como una

26 Paul Ricoeur, Tiempo y narración, Ed. Siglo XXI, México, 2001. En las conclusiones, encontramos un apartado de nombre identidad narrativa, que es la idea sobre la cual desarrolla Sí mismo como otro, pues aquí ya se había planteado la idea de una identidad idem e ipse, pág. 994.

27 Paul Ricoeur, El discurso de la acción, Ed. Cátedra Madrid 1988. En este texto se revisa en diálogo la problemática de el quién de la acción, a la vista del tratamiento propuesto por la analítica. Este quién, que responde a la acción, va a ser la respuesta que ofrece a la identidad narrativa, a la identidad ipse.

28 Paul Ricoeur, Sí mismo como otro, Ed. Siglo XXI, México, 1996, pág. XIII. 
identidad ipse, es una identidad basada en la promesa. En sus variadas concepciones, "mismo" es empleado en el contexto de una comparación, y tiene como contrarios: otro, distinto, diverso, desigual, inverso... y bajo esta contraposición iguala mismidad ${ }^{29}$ con identidad-idem y siguiendo la contrapropuesta propone como antagónico la identidadipse pero solo en la medida en que "sí mismo" no es más que una forma forzada del "sí" sirviendo la expresión "mismo" para identificar que se trata exactamente del ser o de la cosa en cuestión..$^{30}$ No obstante se mantiene la similitud entre el "sí" del "sí mismo" con la idea de "identidad" y de "semejanza". Apoyado en la idea del "sí" pone a jugar la relevancia semántica de la ipseidad y de la mismidad. Eso que hace que algo sea reconocido como el mismo, no encuentra mucha dificultad en su acepción que lo diferencia de eso que hace que algo sea ello mismo, la esencia. Al carecer de esencia o núcleo sólido invariable el ipse, entra en el juego del "sí", y de otro "distinto de sí". Este "distinto de sí" pero que participa de la gramática del "sí" reflexivo, es lo que nunca pierde de vista, pues es sobre este "distinto de sí", donde cimentará la posibilidad de la alteridad. En palabras de nuestro autor: Mientras se permanece en el círculo de la identidad-mismidad, de cualquier otro distinto de sí no ofrece nada de original: "otro" figura, como de paso ya hemos subrayado, en la lista de los antónimos del "mismo" al lado de "contrario", "distinto" y "diverso". ${ }^{31}$ Así lo que interesa es rescatar esta dicotomía entre el "sí mismo" y el "Otro", y romper con esta aparente contraposición que los define uno frente a otro, y cargar con una significación nueva este "sí" que sostiene su

29 Paul Ricoeur, en el Diccionario de hermenéutica, nos dice que bajo el rótulo de mismidad, se colocan varios criterios de identidad; la identidad numérica, de la misma cosa a través de sus apariciones múltiples; la identidad construida sobre la base de las pruebas de identificación y reidentificación de lo mismo; la identidad cualitativa, esto es el parecido extremo de las cosas que pueden ser intercambiables la una por la otra sin pérdida de semántica; y la identidad genética, atestiguada por la continuidad ininterrumpida entre el primero y el último estado del desarrollo. Crf. Ortiz-Oses (Comp.), Diccionario de hermenéutica, Ed. Universidad Deusto, Bilbao, 1998 pág. 325.

30 Ibid. pág. XIII.

31 Ibid. 
hermenéutica del "sí". Una hermenéutica que pone y no contrapone al "sí mismo" contra el Otro. El Otro queda dentro de la lingüisticidad y su condición es igualmente narrativa en la medida en que participa del sí, que lo hace a cada uno en particular un "sí mismo". Más aún, el Otro contribuye a narrarnos.

Finalmente bajo estas líneas directrices puede desplegar su título Sí mismo como otro; no es más que la reflexión, que hace de la alteridad, por medio de las comparaciones sugeridas, una constitutiva de la ipseidad misma.

Sí mismo como otro, sugiere en principio, que la ipseidad del "sí mismo" implica la alteridad en un grado tan íntimo que no puede pensarse una sin la otra, que una pasa más bien a la otra... no sólo como una comparación, sino como una implicación, sí mismo en cuanto ...otro. ${ }^{32}$

\section{EL COGITO FUNDANTE}

Con una formación sobre la significación filosófica de la relevancia del cogito, Ricoeur enlaza la importancia de esta idea con sus pretensiones de fundamento último, sin las cuales lo condena a la intrascendencia. Bajo esta relación se hace responsable de la oscilación dentro de cuyo efecto, el "yo" del "yo pienso", aparece como piedra fundamental de una verdad primaria, de una verdad fundante, inconmovible, inmovible e inmutable. Con lo que se uniforma dentro de la lógica metafísica de Parménides. Sin embargo, el péndulo oscilará hacia el otro extremo y llevará al Cogito a la idea de ilusión improbable. La fundamentación del cogito implica evidentemente su crisis, pues el cogito ha nacido bajo una idea científica, no propiamente filosófica, la idea de la matemática, que sustenta de manera algorítmica su desarrollo. No obstante, esta pretensión de tratar a la filosofía como si fuera una ciencia y buscar en ella una idea inicial que sirva de axioma, forma o deforma el pensamiento de la tradición procedente. Kant, Fichte, Husserl son solamente algunos de los que nuestro autor incluye dentro de esta pretensión, agregaríamos solamente a Edith Stein en Ser finito y ser eterno, ${ }^{33}$ que

\footnotetext{
32 Ibid.

33 Edith Stein, Ser finito y ser eterno, Ed. FCĒ, México, 1994, pág. 39.
} 
arrastra tras de sí las pretensiones metafísicas de su maestro e intenta fundar "nuevamente" la filosofía, como si se tratase de una ciencia. La ambición fundacional atribuida al Cogito cartesiano se deja reconocer desde el principio en el carácter hiperbólico de la duda que abre el espacio de investigación de las Meditaciones..$^{34}$ Descartes nos sugiere un inicio de cero, un nuevo comienzo porque le resultaba preciso fundar este pensamiento para poder establecer algo firme y constante dentro de la ciencia. Sin embargo, no advierte que esta duda se incluye a sí misma, pues a pesar de la aparente radicalización de la misma, no se ha dudado ni del sentido común, ni de la ciencia, ni del lenguaje. Descartes propone una duda que denomina metafísica, en la medida en que ha radicalizado toda opinión sobre los sentidos, y la ha puesto bajo la categoría de sospecha. Aún más, sugiere la hipótesis extrema de la creación de un genio maligno, antagónico de Dios quien, en su infinita bondad y sabiduría sería imposible que se preste a tal engaño. ${ }^{35}$

Es justamente aquí donde el desdoblamiento lingüístico se produce, por las necesidades lógicas del análisis, puesto que si "mis" sentidos me engañan ${ }^{36}$ y no es posible fiarse de ellos, debido a que "el cuerpo" esta bajo el descrédito del goce, llevado al ámbito de lo demoníaco y satanizado por ser pecaminoso, por ello se cree que es justo de ahí de dónde procede el error. El primer salto lingüístico se ha realizado en esta posesión, a la que refiere el "mis" porque bajo esa idea de pertenencia se desprende la posesión del poseído, luego entonces, soy algo distinto de mis sentidos, soy algo distinto de lo que poseo, soy algo distinto del cuerpo. No soy un cuerpo sino que poseo un cuerpo, es la conclusión a la que nos obliga tal utilización de las palabras. Pero ¿dónde queda el yo?, aunque la disolución aún no ha sido consumada, pues todavía queda alguien para decir: yo pongo todo mi empeño en engañarme a mí mismo fingiendo que todos estos pensamientos son falsos e imaginarios. Incluso la hipótesis del genio maligno es una ficción que yo

34 Paul Ricoeur, Sí mismo como otro, Ed. Siglo XXI, México, 1996 pág. XV.

35 Aunque recordemos que el Dios del antiguo testamento y sobre todo el de Job, es un dios que se presta a tales controversias.

36 Es claro que mis sentidos no me engañan pues no emiten juicios. 
creo. ${ }^{37}$ Así y ya puesto en advertencia, la pregunta es, entonces ¿Quién es éste que duda e inventa y trata de engañarse? Un yo desproporcionado, un yo descontextualizado, un yo sin materia, sin situación y sin extensión. Ricoeur no puede menos que advertir que el "yo" que conduce a la duda, y que hace reflexión del Cogito, es tan metafísico e hiperbólico como la misma duda lo es respecto a todos sus contenidos. En verdad no es nadie. ${ }^{38}$

\section{LA FRACTURA DEL YO}

Protegido con la crítica nietzscheana al Cogito, Ricoeur propone englobar toda la tradición de fracturas del yo bajo la rúbrica El cogito quebrado; para ello opone al ego cartesiano el atomismo Nietzscheano, o mejor aún, pone en crudo enfrentamiento, el genio maligno contra la paradoja de tropos lingüístico. ${ }^{39}$ Nietzsche, al criticar la pretensión última del lenguaje como criterio de verdad, arrastra tras de sí al Cogito, como pretensión de verdad, como función fundante, pues no existe verdad que escape a los tropos lingüísticos, no existe pretensión última de verdad que escape a la mera apariencia lingüística. La falta de atino radica en acentuar la arbitrariedad de la causalidad en el mundo fenoménico, y jugar a que el argumento del sueño es válido bajo este criterio, pues nada puede asegurar que la deducción en el sueño siga las mismas normas que la deducción fenoménica, puede ser que el genio maligno nos haga equivocarnos aún en contra de la lógica y que soñando deduzcan cosas que no son ciertas.

Esta última ilusión es la más pérfida, pues pone en acción, en la relación entre el actor y su hacer, la clase de inversión entre el efecto y la causa que hemos relacionado con el tropo de la metonimia, bajo la figura de la metalepsis. De este modo, tomamos como causa, bajo el título del yo, lo que es el efecto de su propio efecto. ${ }^{40}$

37 Ibid. p. XVI.

38 Ibidem.

39 Friedrich, Nietzsche, Sobre verdad y mentira en sentido extramoral, Ed. Tecnos, Madrid, 1996.

40 Paul Ricoeur, op. cit., pág. XXVIIl La trampa radica en poner como fundamento a un cogito que era resultado del pensar, luego como es resultado no puede ser tomado como inicio, a este error tan común de tomar el efecto por la causa se le conoce como metalepsis. 
Nada hay pues inherente al cogito que nos haga deducir el yo. Antes bien del yo se podría, en determinado caso, seguir el cogito y Nietzsche lo radicaliza al acentuar que el "yo" no aparece como inherente al cogito sino como una interpretación de tipo causal. Pero esto no es más que una exageración del hábito que nos sugiere que detrás de una acción, debemos encadenar a un sujeto responsable de la acción a un ¿Quién? Por ello Nietzsche nos dice: dudo mejor que Descartes, puesto que el Cogito también es dudoso. Con la duda puesta sobre el cogito nuestro autor no necesita más que extender el pensamiento sobre esta duda, junto con los maestros de la sospecha él sospecha, en efecto, que esta duda no es tan radical como se presenta, y que no solamente el ego cartesiano es tan metafísico como la duda, sino que además la duda misma no es tan radical como se presenta, pues no es llevada hasta el extremo de dudar del yo. Sin más, Ricoeur de frente a Nietzsche duda no solamente de Descartes sino de Nietzsche e instaura la fractura que buscaba, con la cual replantear el pensamiento del yo, ahora extrayéndolo del solipsismo del que solamente lo podría sacar Dios, y poniéndolo de lado del Otro, de una alteridad que le permita salir de sí mismo y entenderse como autre. Je-autre. ${ }^{41}$

\section{LA GÉNESIS DE LA HERMENÉUTICA DEL SÍ}

Si atendemos a la trayectoria del autor podemos advertir que sus libros $^{42}$ son sin más el testimonio de un transcurrir filosófico con la verdad de lo voluntario y de lo involuntario, pero no en su vertiente

41. Imre Kertész desarrollará todo su libro Yo, otro, bajo esta idea de ser una narración del otro. Ver. Imre Kertész, Yo, otro, Ed. Acantilado, Barcelona 2002.

42. Sí mismo como otro, obra que publica en francés en 1990, cuya edición en español aparece en 1996 (después de haber visto la luz Finitud y culpabilidad, en 1960; su Ensayo sobre Freud una interpretación de la cultura, en 1965; El conflicto de las interpretaciones, 1969; La metáfora viva, 1975; los tres volúmenes de Tiempo y narración, 1983-1984; Del texto a la acción y En la escuela de la fenomenología 1986; por citar solamente algunos de los más importantes) representan la síntesis de su reflexión sobre el sujeto. Citado por María de los Ángeles San Emeterio, P. Ricoeur, palabra de liberación, Ed. UNAM, México 2005. Coordinadora M. Rosa Palazón, pág. 259. 
metafísica como lo intenta Schopenhauer, sino en su encarnación concreta. La filosofía del sujeto que parte de la fenomenología y lo conduce a Freud, para después desembocarlo en la hermenéutica que él mismo denomina (junto con la obra de Foucault,) la hermenéutica del "si", ${ }^{43}$ es el intento por desarrollar un pensamiento de este auto reflexivo que incluye no solamente al "yo" sino al "tú", y al "nosotros". Sí mismo como otro, es el producto de esta reflexión sobre la filosofía del sujeto. Tres son sus raíces principales, la primera es la necesidad de reflexionar sobre la identidad narrativa con la que concluye el tercer volumen de Tiempo y narración, así que ahí está anclada su raíz. La segunda es el tiempo que proporciona ser becario como participante en el proyecto para la universidad de Edimburgo en las Gifford Lectures, con la intención de hacer un balance de las filosofías del sujeto. La tercera es el plan que sobre la alteridad había diseñado junto a E. Levinas, para desarrollar un libro. La promesa hecha de escribir libro sobre la alteridad del "yo" marca profundamente a nuestro autor que no puede menos que cumplirla y escribe Sí mismo como otro, obra donde queda clara la tendencia levinasiana y sobre todo, las críticas a este último. Finalmente después de un breve balance de las filosofías del sujeto que constituyen solamente el prólogo a la obra, llega a la conclusión que le servirá de inicio: el "yo" de las filosofías del sujeto es atopos, sin lugar asegurado en el discurso. ${ }^{44}$

\section{LA HERMENÉUTICA DEL SÍ}

Situándose más allá de la aparente evidencia del cogito, dejando atrás la idea de un anti cogito, y de un cogito fracturado, se centra en la vía de la semántica del quién, dirección que ya había transitado en El discurso de la acción ${ }^{45}$ y que ahora le sirve no solamente como la manera de responder al agente de la acción, sino a la necesidad de proyectar una solución a las paradojas que contrae el tiempo sobre la identidad; para

\footnotetext{
43 Ver. Michel Foucault, Dits et écrits, Editions Gallimard, Paris 1993 pág. 121.

44 Paul Ricoeur, op. cit., pág. XXVIII.

45 Paul Ricoeur, El discurso de la acción, Ed. Cátedra, Madrid, 1988.
} 
así unir no solamente a las filosofías del $\operatorname{cogito}^{46}$ o de la alteridad ${ }^{47} \sin 0$ a ambas en una teoría que sea equivalente. Que no se extravíe en el otro, y que no regrese al yo como criterio fundante, algo que pueda asegurar su lugar dentro del discurso. Esta búsqueda obedece a la misma respuesta de la pregunta por el ¿Quién de la acción?

Daremos una forma interrogativa a esta perspectiva, introduciendo por la pregunta ¿quién? todas las relaciones relativas a la problemática del sí. Cuatro subconjuntos corresponden a cuatro maneras de interrogar: ¿quién habla?, ¿quién actúa?, ¿quién narra?, ¿quién es el sujeto moral de imputación? ${ }^{48}$

Las primeras dos respuestas han sido tratadas por la filosofía del lenguaje, los derroteros han sido la semántica y la pragmática y han tenido repercusión en las construcciones teóricas de la filosofía analítica de lengua inglesa. No es gratuito este rodeo por la filosofía analítica, sino que enriquece a la hermenéutica del "sí" pues la llena de promesas; el mantenimiento de estas promesas es lo que le dan identidad. ${ }^{49} \mathrm{La}$ pregunta por la identidad y por el tiempo, nos hace preguntarnos por la identidad de lo "sujeto al tiempo" así, la pregunta se divide en dos cuestiones ¿de quién hablamos cuando designamos según el modo referencial a la persona como distinta de las cosas? y ¿quién habla designándose a sí mismo como locutor?. ${ }^{50}$ Estas dos preguntas sesgan los análisis propios del autor, respondiendo al ¿quién? diseña la primera faz de la hermenéutica del sí, como el agente de la acción; respondiendo a la segunda que es la fundamental y la que más propiamente le interesa, pues lo regresa a la moral y lo emparenta más propiamente con la poesía Aristotélica. ${ }^{51}$

46 Paul Ricoeur, piensa que la tradición del cogito engloba a Kant, Fichte, Nietzsche, Husserl, etc. Quienes piensan aún de manera moderna, es decir bajo el principio de organización, que para Descartes fue el cogito.

47 Por filosofía de la alteridad entiende el ala neo francesa encabezada por Emanuel Levinas Oliver A. Parrour y él mismo.

${ }_{48}$ Paul Ricoeur, op cit. pág. XXIX.

49 Ver Abel Oliver, La promesa es la regla, Ed. Michalon, Paris, 1997. La traducción es nuestra.

50 Paul Ricoeur, op. cit. pág. XXX.

5. Ver Paul Ricoeur, La metáfora viva, Ed. Trotta, Madrid, 2001. 
¿Quién habla designándose a sí mismo como locutor? El interlocutor es el eje de la hermenéutica del "sí", es la noción que conjunta el diseño y la intención, engloba lo voluntario y lo involuntario, responde no sólo a la filosofía del sujeto sino a la analítica que lo había tratado como objeto dentro del mundo y a la hermenéutica que le da la posibilidad de interpretarse en primera persona, en este interpretarse se da su ser. El hombre moderno es un hombre creador, un hombre que piensa en contra de su supuesto y antiguo creador y lo primero que crea cuando piensa, es a sí mismo; pienso por tanto existo no es más que una acción de auto creación, que encuentra en el orden del mundo creado por dios, la manera de auto proclamarse. De auto inventarse. La hermenéutica del sí, no dista mucho de esto, pues su hacer radica en otro movimiento de autofundarse como interpretación, como un ser que se debe a los otros porque los otros se deben a él. Es una auto creación que ha dejado atrás el solipsismo y a la hora de crearse requiere del Otro $^{52}$ para existir dentro del mundo, para hacerlo habitable. La primera persona es el supuesto esencial de la interpretación, es decir, es necesario como aspecto del conocimiento de la tercera persona, acerca de la mente de los otros, y del significado de sus palabras. ${ }^{53}$ La hermenéutica del sujeto, ya no es la filosofía del sujeto, ya no está centrada en la primera persona sino en la relación con la alteridad que es la que da horizonte de explicación al nuevo yo, un yo otro. En palabras de Rimbaud: Yo es Otro.

IDENTIDAD Y NARRACIÓN

Sobre la pregunta por el ¿quién de la acción? y sobre la reflexión de la acción dentro del tiempo, se pueden obtener dos variantes que son: agentes de la acción y tiempo. La pregunta obligada en este punto es ¿cómo es posible una identidad dentro de la acción que está sujeta

52 Hilary Putnam ha trabajado en esta línea, tratando de dejar atrás el solipsismo y demostrar la existencia de otras mentes, así como el contexto donde las oraciones sobre estas mentes tienen sentido. Ver Otras mentes, Ed. UNAM, México, 1984 pág. 13.

53 Donald, Davidson, Mente, mundo y acción, Ed. Paidós, Barcelona, 1992.

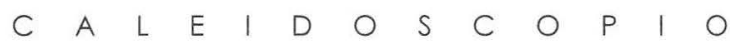


al tiempo?. Un vástago híbrido entre la teoría narrativa de la historia y la ficción ${ }^{54}$ lo constituye la asignación de la identidad; identidad que Ricoeur bautiza como identidad narrativa y de la cual echa mano para postular su solución.

\footnotetext{
Esta identidad narrativa es de la mayor importancia sobre una investigación entre la identidad... de los sujetos, pues ella posee el mismo carácter dramático y narrativo que a menudo corremos el riesgo de confundir con la identidad de una sustancia o una estructura..$^{55}$
}

La Identidad que está contextualizada bajo la pertenencia de un individuo a una práctica, hace de la identidad algo imputable: hace de la identidad una cuestión de responsabilidad pues se sigue pensado la acción como imputable o como responsabilidad sobre un actor. Así decir identidad de un individuo o de una comunidad es responder a la pregunta ¿quién ha hecho esta acción? ¿quién es su agente, su autor? ${ }^{56}$ y la respuesta narrativa que hace de un agente idéntico a sí mismo es el nombre. ${ }^{57}$ La pregunta puede ser respondida de dos maneras; en el ámbito legal trayendo a colisión al sujeto en cuestión, en el ámbito literario presentando el nombre de un personaje, nombre que engloba bajo la idea fenomenológica de la acción al agente de dicha acción. El nombre es la respuesta en la literatura por el agente responsable de la acción. Cuando Robert Musil escribe "no soy nada" enfrentamos una respuesta reducida a su mínima expresión. ${ }^{58}$ Nos enfrentamos a un personaje que se niega como tal, que intenta diluir su condición de identidad a través de negar sus posibilidades narrativas; sin embargo aún ahí tenemos una respuesta, tenemos alguien a quien se hace responsable de la negación de su historia, de la negación de su yo. Pero ¿qué justifica que se tenga al sujeto de la acción, así designado por su nombre, como el mismo

54 Paul Ricoeur, Relato: historia y ficción, Ed. Dosfilos, México, 1994.

55 Paul Ricoeur, Lo justo, Ed. Caparrós, Madrid, 1999, pág. 41.

56 Paul Ricoeur, Tiempo y narración, Ed. Siglo XXI, México 2001, pág. 997.

57 Sobre la utilización de los nombres propios, Ver M. Beuchot, Tópicos de filosofía y lenguaje. Ed. UNAM pág. 77 y ss.

58 Paul Ricoeur, Historia y narratividad, Ed. Paidós, Barcelona, 1999, pág. 223. 
a lo largo de una vida que se extiende desde su nacimiento hasta su muerte?59 Qué hay en nuestro análisis hermenéutico que nos haga atribuirle la misma identidad a una semilla que a un árbol, qué es lo que nos hace en cuestión narrativa, dejar atrás de manera resuelta las dificultades planteadas por Hume. La respuesta solamente la encontramos en los límites del juego de la narración, ya que responder a la pregunta por el ¿quién? es sin lugar a dudas ofrecer una historia, y así comenzamos a aventurar nuestras conclusiones. La identidad del sujeto narrativo, la constituye esta historia que se auto imputa. Cuando se pregunta por el "qué" la respuesta nos conduce al callejón sin salida de la analítica sustancialista, pues nos obliga a hacer un adjetivo sustancial. Mientras que si la pregunta se dirige al "quién" la respuesta toma un sesgo lingüístico, pues se ofrece una historia que responde auto imputándose actos lingüísticos que no solamente lo hacen responsable, sino que además lo constituyen. Por lo tanto la propia identidad del quién no es más que una identidad narrativa. ${ }^{60}$ Sin el análisis de la narración, la identidad no salva las aporías temporales de Hume y está condenada a un callejón que no la conduce a ningún lado, o se vacía el análisis de la noción de temporalidad y se hace del sujeto alguien idéntico a sí mismo, dejando de lado su diversidad, o se acepta que este sujeto no es posible pensarlo como idéntico a sí mismo. Pues la necesidad de una identidad temporal nos ha conducido no sólo al sustancialismo de Descartes, sino al esencialismo de Aristóteles. El dilema desaparece si la identidad entendida en un sentido de un sí mismo (ídem), se sustituye por un sí mismo (ipse); la diferencia entre ídem e ipse no es otra que la diferencia entre una identidad sustancial o formal y la identidad narrativa. ${ }^{61}$ Pretende así que la identidad ipse salve las nociones de contradicción, que acarrea la identidad ídem, pues ésta proviene no de la noción de mismidad sino de la noción de narratividad, noción que en este momento propone como sujeta al tiempo; por ello la identidad sujeta al tiempo tiene en

\footnotetext{
59 Paul Ricoeur, Tiempo y narración, Ed. Siglo XXI, México, 2001, pág. 997

60 Ibid.

61 Ibid.
} 
sí misma la posibilidad de mantenerse, de la misma manera en que se mantiene un sujeto responsable de una acción a través de una na rración. El nombre constituye una de sus posibilidades de identidad, ya que la identidad ipse puede constituirse a sí misma por el cambio temporal, pues engloba la multiplicidad de la constitución en la historia de una vida. Así el sujeto aparece constituido como lector y como escritor de su propia vida según el deseo de Proust. ${ }^{62}$

\section{EL PROBLEMA. DE LA IDENTIDAD}

R. Musil ${ }^{63}$ junto con Borges ${ }^{64}$ y Klossowsky ${ }^{65}$, forman la triada que J. G. Ponce analiza en la errancia sin fin, donde la disolución de la identidad narrativa es la temática principal. Para estos tres autores nos dice que: el carácter de toda identidad es la imposibilidad de definirla y por lo tanto su inexistencia aún en términos gramaticales. ${ }^{66}$ Ante la imposibilidad de una definición de la identidad, solamente nos queda el diálogo, la palabra, palabra que contesta, que como en Musil se niega a ser algo, nos enfrentamos con la respuesta de un quién, que habla, de una identidad ipse que habla desde un "yo" anclado en la mismidad. Necesitamos un punto fijo, la mismidad, para seguir hablando.$^{67}$ Cuando la empresa apunta a la alteridad es necesario anclarse en la narración que funcione como eje director de nuestra búsqueda, de lo contrario la alteridad nos tragaría, como el mar en el que naufraga la mismidad y es disuelta por la alteridad. Una alteridad sin un punto de retorno como el yo-ipse, es una alteridad tan radical y extraviada como las filosofías del sujeto. Ricoeur sabe de este peligro y por ello, la ipseidad contiene un poco de mismidad o un poco de alteridad. Así la identificación de un personaje que pregunta por el "quién" obtiene una respuesta en la narración de la vida de quien

\footnotetext{
62 Ibid. pág. 998

63 Robert Musil, El hombre sin atributos, Ed. Seix Barral, México, 2000.

64 Jorge L. Borges, Obras completas, Ed. Emecé, Buenos Aires, 1999.

65 Klossowsky Roberta esta noche, Ed, Tusquets, Barcelona, 1977.

${ }^{66}$ Juan G. Ponce, La errancia sin fin, Ed. Nueva imagen, México, 2001, pág. 14.

67 Columba C. P., Ricoeur, palabra de liberación, Ed. UNAM México, 2005, pág. 171.
} 
se ofrece dicha respuesta; soy palabra en diálogo, soy narración contada desde las circunstancias. Con ello queda claro la dimensión temporal que arrastra tras de sí el sí mismo. Un sí mismo sujeto al tiempo y a la interpretación, un sí mismo hecho de narración temporal e interpretación circunstancial. Esta es la intención de repasar los particulares de base de Strawson, ${ }^{68}$ el reconocer a la persona como inmersa en la lingüisticidad y sujeta al tiempo. Así vuelve a poner el análisis de la persona en la perspectiva de la referencia identificante y del agente en el ámbito de la semántica de la acción. ${ }^{69}$ En la hermenéutica del sí, el punto fijo lo constituye la historia, pues la génesis de la historia se encuentra en la misma historia. ${ }^{70}$ Así, la identidad personal solamente puede articularse dentro de la dimensión temporal de la existencia humana. ${ }^{71}$ La génesis de la hermenéutica del sí, está anclada en la teoría narrativa. En Ricoeur la escritura es la construcción del personaje y en su análisis encuentra la manera de interpretar la identidad humana. Para él no somos más que personajes dentro de la temporalidad histórica de la cual formamos parte, es decir, escribimos la historia y somos escritos por ella. La otra dimensión que no quiere perder de vista dentro de su hermenéutica es la dimensión ética, puesto que los sujetos capaces de acción tienen que ser capaces de responsabilidad, por ello retoma la noción de causalidad fenomenológica que imputa acciones como responsabilidad de agentes, o hace a los agentes responsables de la cadena causal de los eventos. Así no existe, según nuestro autor, narración éticamente neutra y completaríamos que tampoco hay interpretación éticamente neutra. Narrar e interpretar son dos fases de un mismo movimiento, son como el anverso y el reverso de la moneda, somos como lo dice $G$.

\footnotetext{
68 Ver Paul Ricoeur, Sí mismo como otro, Ed. Siglo XXI, México 1996, pág. 6

69 Columba C. P., Ricoeur, palabra de liberación, Ed. UNAM, México, 2005. Coordinadora, M. Rosa Palazón, pág. 171.

70 Historia que comienza ya dentro de la historia de quien la escribe, aunque ha tenido comienzo dentro de la historia social. Cuando decimos que la historia se ha formado en la historia, es a este tipo de historias globales o abarcativas a las que nos referimos.

71 Paul Ricoeur, op. cit., pág. 107.
}

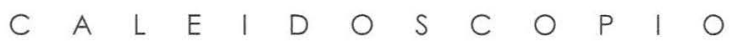


Marched, los lados complementarios del pase, el émbolo y el símbolo ${ }^{72}$ Con lo que los personajes están sujetos a la lógica de la imputación. Aunque la imputación tiene varios caminos como lo son el de la punición, el reconocimiento y la legalidad; al reconocimiento le concierne más la lógica de la edificación. La hermenéutica del sí contrae tintes edificantes, sobre todo en la dimensión en que el personaje puede auto narrarse y con ello formarse como actor dentro de la historia.

La noción de identidad narrativa está formada en la mismidad, esto es lo que me acontece y es propiamente lo que soy, pues me acontece a mí; si otros fueran los eventos que me acontecieran, mi mismidad sería distinta. Por ello, yo soy eso que me acontece, eso que me hace es lo que constituye la historia que narro de mí mismo. De cambiar los eventos cambiaría lo que soy, y con ello cambiaría la forma de narrarme. Narración y eventos son el péndulo donde se despliega la mismidad como ipse.

\section{PROBLEMA DE LA IDENTIDAD PERSONAL}

En la personalidad confluyen las más importantes problemáticas en cuanto a la identidad. La identidad presenta varios usos que hacen no sólo la problemática, sino que sesgan las posibles respuestas.

Por un lado tenemos la identidad como mismidad (latín ídem; inglés sameness; alemán: Gleichheit); por otro lado la identidad como ipseidad (latín: ipse; inglés: selfhood; alemán: Selbstheit) la ipseidad como se ha afirmado en numerosas ocasiones no es la mismidad. ${ }^{73}$

La problemática de la identidad al ser elevada a la unicidad de la primera persona y sobre todo en su uso autoreflexivo, cuando "se" narra, constituye la problemática central de la dimensión temporal. Los intentos de identidad como ídem e ipse, no tienen mayor punto de fuga que la necesidad de la permanencia dentro del tiempo de la primera persona que ahora se narra, que ahora se imputa un "yo" como 
si fuese un acto y cuyo acto es constituyente de esta locución "yo" primera persona, y que no significa otra cosa en nuestro autor que: yo hablo, yo nombro, yo narro.

La cuestión de la identidad como permanencia en el tiempo, estaba planteada por la identidad idem en Hume, como identidad perfecta. Por el contrario en el horizonte teórico de la mismidad, ya planteado por Locke, la mismidad es un concepto de relación y una relación de relaciones. A la cabeza se sitúa la identidad numérica, así de dos veces que ocurre una cosa designada con un mismo nombre decimos que ocurre "una sola y misma cosa" identidad aquí significa unicidad, lo contrario es pluralidad. ${ }^{74}$ El primer modelo de identidad es el de reidentificación cuando dos eventos son reconocidos como el mismo o decimos que sucede " $n$ " veces el mismo evento.

En segundo lugar, tenemos la identidad cualitativa, que se da cuando se predica de dos objetos que son idénticos y que no es más que decir que el valor de intercambio resulta imperceptible. De hecho el umbral de percepción tiene mucho que ver con la cuestión de la identificación. ${ }^{75}$ Estos dos tipos de criterios (identidad como reidentificación y cualitativa) suelen citarse a la hora de construir una identidad sobre los sujetos. Una identidad que se confunde con identidad numérica. La cuestión de la identificación en el marco de la legalidad, tiene para sí sus propios mecanismos de interpretación. La propia semejanza debe entenderse como una tensión entre identidad y diferencia ${ }^{76}$ del mismo modo en que la primera línea hermenéutica fue desarrollada por Aristóteles en pro de la filosofía y contra la poética; al pedir como criterio la verosimilitud, el juego de la identificación de un sujeto en un marco legal propone sus normas que son las huellas o rastros que un individuo deja dentro de una escena y con las que es posible ubicarlo en un tiempo determinado en el lugar deseado. Caso contrario, y esto ocurre con

74 Ibid. pág. 110

75. En un nivel incrementado de percepción, como el que nos propone Borges en Funes el memorioso, la identidad sería imposible, pues es radicalmente distinto el perro de las tres visto de frente, que el de las tres quince visto de perfil.

76 Paul Ricoeur, La metáfora viva, Ed. Trotta, Madrid, 2001, pág. 12.

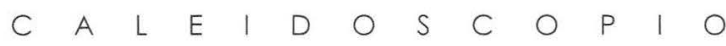


frecuencia, es que el personaje puede alegar que no fue él. La identidad dentro del ámbito legal pone en la mesa otro tipo de discusión sobre la identidad que ofrece sus propios mecanismos identificatorios.

Otra característica que va a fraguar el criterio de identidad narrativa dentro de la hermenéutica del "sí", es la continuidad ininterrumpida, entre el primero y último desarrollo de lo que consideramos el mismo individuo; este criterio prevalece en todos los casos en los que el crecimiento, el envejecimiento, actúan como factores de desemejanza. ${ }^{77}$ Con este criterio de "continuidad ininterrumpida" Ricoeur trata de solventar las paradojas de la identificación de una semilla con un árbol, o de un animal del que se predica que es el mismo desde que es un embrión hasta el momento de su muerte. Si aceptamos este criterio de continuidad ininterrumpida la pregunta obligada es, qué es eso que permanecía ininterrumpidamente. Ricoeur nos diría que es la persona, pero esto no contrae un núcleo sólido ni invariable.

Por ello, la amenaza que representa para la identidad solo queda enteramente conjurada si se puede plantear, en la base de la similitud y de la continuidad ininterrumpida de cambio, un principio de permanencia en el tiempo: será por ejemplo como la estructura invariable de una herramienta cuyas piezas hemos cambiado progresivamente. ${ }^{78}$

En este caso qué es lo que se mantiene sino la función para la cual fue hecha y aún cumple.

\section{El CÓDIGO GENÉTICO}

Todo este rodeo fue con un propósito determinado, el de tratar la problemática del código genético que se presenta como algo invariable. Lo que en el código genético permanece es la unión de una agrupación, de una estructura, es la organización de un sistema combinatorio.

77 Paul, Ricoeur, Sí mismo como otro, Ed. Siglo XXI, México, 1996, pág. 111.

78. Ibid. 
El criterio más fuerte que pueda darse, y que confirma el carácter relacional de la identidad, que no aparece en la antigua formulación de la sustancia, ni entre las categorías de relación, pero que Kant estableció al clasificar la sustancia entre las categorías de relación como condición de posibilidad de pensar el cambio en cuanto llega a algo que no cambia, al menos en el momento de la atribución del accidente de la sustancia, la permanencia en el tiempo se convierte así en la trascendencia de la identidad numérica. ${ }^{79}$

Se sesga con esto toda la problemática de la identidad, ya que es una problemática que tiende a buscar algo que permanezca invariable en el tiempo.

El desplazamiento en Kant de la idea de sustancia (aquí código genético) desde el plano ontológico al trascendental; está señalado por la simple correspondencia entre la categoría, su esquema y el principio (o juicio primero). A la sustancia primera, categoría de la relación, corresponde el esquema que explica su constitución temporal, a saber: la permanencia de lo real en el tiempo; es decir; la representación de lo real como sustrato de la determinación empírica del tiempo en general, sustrato que, consiguientemente, permanece mientras cambia todo lo demás... así la sustancia persiste a todo cambio de los fenómenos y su cantidad no aumenta ni disminuye en la naturaleza. ${ }^{80}$

El código genético no resulta una sustancia sino una relación, y la tesis según la cual la identidad ipse no posee ningún núcleo sólido que sea sustancializable o invariable, se salva al emparentar directamente la ipseidad con la relación, no con la sustancia. ${ }^{81}$ La relación de un objeto sujeto al tiempo es su cambio, y este cambio no constituye sustancia alguna, por ello el código genético no constituye sustancia alguna sino relación. Así la identidad como sustancial, no es más que un neboluso término honorífico que gustosamente aplicamos a nosotros mismos y a los demás. ${ }^{82}$ Una ficción que predicamos de nosotros mismos.

Bajo el tema de lo involuntario, y más precisamente de lo involuntario absoluto, Ricoeur unos diez años antes, situaba al carácter y ahora

79 Ibid.

so Ibid.

81 Derek Parfit, Lewis, Perry y lo que importa, Ed. UNAM, México, 1985 pág. 5 y ss.

82 Daniel, Dentt, Condiciones de la cualidad de persona, Ed. UNAM, México, 1989 pág. 6. 
al código genético, en esta fase de las relaciones no de las sustancias. El carácter, diría él, designa el conjunto de disposiciones duraderas en las que reconocemos a una persona. En este aspecto, el carácter puede construir el punto límite en que la problemática del ipse se vuelve indiscernible de la del ídem e inclina a no distinguir una de otro ${ }^{83}$ Lo involuntario como lo es el carácter y el código genético no solamente determinan el límite interpretativo de la problemática de la identidad sino que son una de las principales objeciones a la identidad ipse, pues tanto el carácter como el código genético son cuestiones que permanecen y nuestro autor no solamente atina a decir que vuelven el análisis indistinguible.

\section{PROBLEMÁTICAS EN TORNO A LO CORPÓREO}

La primera vez que nuestro autor, dentro de la temática de la mismidad, aborda el cuerpo como carne, lo hace en referencia a la obra de P. F. Strawson, Individuos. La temática gira en torno a la forma de adscribir predicados psíquicos y físicos inconexos entre sí y cómo es que estos pueden ser atribuidos a una misma entidad o persona. La problemática la resuelve la semántica de la transferencia, todo lo que puedo transferir o donar es mío, lo que no es posible transferir o donar, no puede ser predicado de mi pertenencia. ${ }^{84}$ Se limita a la acepción según la cual las personas son también cuerpos por una restricción del lenguaje cuando hablamos de las cosas como lo hacemos. ${ }^{85}$ La relación de que cada persona sea un cuerpo y no posea un cuerpo, es en la medida en que cada persona es un cuerpo para sí. La problemática se remonta hasta Schopenhauer, que ahora se plantea de la siguiente manera: ¿Cómo es que un cuerpo

83 Ricoeur, P., Op. Cit. 1996 pág. 115.

84 Strawson, Individuos, Ed. Taurus, Madrid, 1989. Advirtamos que la obra se ha realizado en un momento donde los transplantes no eran algo tan comunes, que cualquiera supiera ni imaginara. La cuestión del transplante es problemática, porque la semántica utilizada nos remite que podemos donar "nuestro cuerpo", sin embargo la objeción se salva si entendemos que no donamos nuestro cuerpo sino a nosotros mismos.

85 Ricoeur, Op. Cit., 1996 pág. 354 
pertenece a dos esferas distintas, a la de los objetos y a la del en sí? La problemática ontológica siguiendo a Wittgenstein es: Si el mundo es todo lo que es el caso, ${ }^{86}$ cómo puede una acción constituir al mismo tiempo un acontecimiento del mundo, dado que la acción es considerada como algo fuera del mundo, y a su vez hace referente al autor de la acción que tampoco se considera parte del mundo, pues según la ontología wittgensteiniana, el sujeto es el límite del mundo. La semántica de la acción tiene que unir el mundo y el cuerpo, Schopenhauer sospechaba que lo cárnico era el límite entre lo numénico y lo fenomenológico. Para Ricoeur, el cuerpo es el lugar -en sentido fuerte- de esa pertenencia gracias a la cual el sí puede poner su sello sobre estos acontecimientos que son las acciones; ${ }^{87} \mathrm{el}$ cuerpo es el modo de que el sí, actué. La cuestión de la carne es una temática que se obtiene por medio de disociaciones, primero hay que distinguir y separar, como lo hace Maine Biran, la noción de existencia y de sustancia ${ }^{88}$ Pues la noción de existencia tiene una vinculación con la acción que no posee la de sustancia. Por lo tanto decir yo, es decir yo quiero, muevo, hago ${ }^{89}$ Este autor citado por Ricoeur, introduce al cuerpo propio, en las regiones de la certeza no representativa. Con lo que hace del cuerpo una certeza en sí, anterior a la representación, una unión indisoluble entre el yo y el cuerpo. La noción de corporeidad representa grados crecientes de pasividad. El mundo es percibido en la pasividad del cuerpo, el sufrimiento es la reducción de la acción corporal y el crecimiento de su pasividad en la afección. Esta pasividad sostiene la duda de Descartes pues esta duda descansa en el espectáculo de las cosas. Y si Descartes puede dudar de que hay un cuerpo es porque se hace de él una imagen que la duda reduce fácilmente a ensueño. ${ }^{90}$

Para nuestro autor el pensador central de la ontología de la carne es Husserl, porque es el primero en pensar la distinción entre cuerpo y

86 Ludwig Wittgenstein, L., Tractatus Logico-Philosophicus (trad. Jacobo Muñoz e Isidoro Reguera) Ed. Alianza, Madrid, 1987, pág. 49.

87 Ricoeur, Op. Cit., 1996, pág. 354.

88 Maine Biran, Sendas de ideología, Ed. Rodríguez, México, 1964, pág 34.

89 Ibid, pág. 356.

90 Ricoeur, Op. Cit., 1996, pág. 356. Nota al pie.

I


carne, que ocupa en las Meditaciones cartesianas ${ }^{91}$ una posición estratégica, en virtud de la cual no debería existir más que una etapa hacia la constitución de la naturaleza en común, es decir, intersubjetivamente fundada. ${ }^{92}$ En primera instancia, la carne está ligada a la producción y se analiza dentro de la noción del posible apareamiento. Para producir una nueva carne, la distinción entre la carne y lo corpóreo radica en que lo corpóreo se relaciona, no con la producción sino con la percepción, mientras que la carne es entendida como condición primera de estar yecto en el mundo. Lo cárnico es nuestra primera condición de estar dentro del mundo, de la misma manera en que los objetos se encuentran dentro del mundo, ni siquiera hay una noción de propiedad, no se puede hablar de este ser arrojado al mundo, de este ser abyecto, de una pertenencia de la carne. En este momento la carne solamente se queda en egología distante, no se introduce en la hermenéutica del "sí". La carne mueve, puede ocupar un lugar en el espacio, el cuerpo siente, quiere y su lugar va más allá del espacio, pues proyecta. Hace posesiones, incluso espaciales o terrenales, es capaz de dibujar una topología sobre la carne.$^{93}$ Lo que la naturaleza nos exige pensar, antes de la construcción del alter ego, es el yo en cuanto carne, la construcción intersubjetiva de la naturaleza que ha producido, por medio del proceso sexual, más carne. La carne se presenta así como el polo de referencia de todos los cuerpos que provienen de la naturaleza. ${ }^{94}$ Esta noción de yecto, de proyecto arrojado, de ser en el mundo como carne, cobra su radicalidad bajo la idea de alteridad primera, alteridad que es afectada por otro

91 Edmund Husserl, Meditaciones cartesianas, Ed. FCE, México, 2004.

92 Paul, Ricoeur, Op. Cit. 1996, pág. 357.

93 Para Michel. Foucault, la carne es la condición primera de las personas, es el lugar donde originariamente se recibe el castigo, por ser la carne el principio de identidad válido para los antiguos procesos legales. Ver Michel Foucault, Vigilar y castigar, Ed. Siglo XXI, México, 1989, pág. 38 y ss.

94 Paul Ricoeur, Op. Cit. 1996, pág. 359.

95 Aquí Ricoeur está en contra de la ontología que sustenta la noción de alteridad de Husserl quien no cree que el otro parta de un yo, por lo que podamos decir y obtener un yo otro. 
que la diseña y que hace aparecer el primer rasgo del "sí", como una mismidad que concede y deja atrás su noción de carne, para entrar en el ámbito de lo corpóreo.

\section{AltERIDAD y CUERPO}

Con la carne puesta en este lugar de lo dado, mucho antes de la aparición del alter ego, Ricoeur puede salvar eso que nos hace hombres, eso que nos ayuda a construir nuestra noción del mundo, de nosotros mismos e incluso nos hereda el lenguaje, el Otro. Es en esta alteridad donde el hombre encuentra su manera de dejar tras de sí la carne y construir el cuerpo, no bajo una intencionalidad de la conciencia como lo señala Husserl, ${ }^{95}$ sino como una recepción primordial del otro. La idea de que el Otro puede ser entendido como un yo, distinto de mí, como un yo otro, no es aceptable para la ontología de nuestro autor, que cree que el yo en esa medida pierde su significado y nos arroja a un mundo de yos solitarios, no solipsistas. Contra esto ha esbozado su idea del reflexivo sí, del sí mismo pues el Otro también es un "sí mismo". Una nueva dialéctica de lo Mismo y de lo Otro es suscitada por esta hermenéutica que, de múltiples formas, atestigua que el otro no es solo la contra partida del Mismo, sino que pertenece a la constitución íntima de su sentido. ${ }^{96} \mathrm{Sin}$ embargo, ni la propuesta de Husserl de reducción del diseño del sí al alter ego, ni la de Levinas de reservarle al Otro ${ }^{97}$ la iniciación exclusiva, lo satisfacen. Busca una relación que haga justicia a la primacía de la estima del sí y a la comunicación por parte del otro de la justicia. Pues el otro es el que nos enseña a ser justo, es con él con quien discutimos nuestras nociones de preciso, de sobra y demora de justicia. ${ }^{98}$ Contra Husserl argumenta que éste entiende al Otro como Otro distinto

96 Paul Ricoeur, op. cit. 1997, pág. 365

97 Emanuel Levinas, Éthique et Infini, Ed. Le livre de poche, París, 1982, pág.28.

98 Precisamente por ello, los trabajos posteriores de nuestro autor desarrollarán la noción de justicia y alteridad. Ver Paul Ricoeur, Lo justo, Ed. Caparrós, Madrid, 1999.

99 Paul Ricoeur, Sí mismo como otro, Ed. Siglo XXI, México, 1996, pág. 370. 
de sí, pero bajo su análisis de la mismidad como ipseidad, el yo no solamente incluye al otro sino que el otro incluye el yo. Para Ricoeur Otro no significa Otro distinto de mí, sino otro complementario. En contra de Levinas sopesa el concepto de Alteridad radical, pues el lituano supone que no hay un resto propio y todo se lo debe al Otro. El Otro siempre ha sido un sujeto de mi pensamiento, pero no hay que dejar de lado que el Otro también me sujeta en su pensamiento. No puedo ser totalmente del Otro, porque el Otro predica de sí, lo mismo, esto es, una deuda conmigo. Uno y Otro se deben a esta relación que les da sustento. Así que mi carne sea un cuerpo ino implica que aparezca como tal ante los ojos del otro? Sólo una carne para mí, que es un cuerpo para el Otro, puede desempeñar el papel de primer análogon en la traslación analógica de la carne a carne. ${ }^{99}$ El otro es el análogon entre mi mismidad cárnica y mi posibilidad de corporeidad, el otro me reconoce como otro ante sus ojos, como alguien no acabado, abierto a la infinitud de posibilidades con las que cuenta la libertad. El Otro me hace hombre, y me llama a la justicia. Como un modo de ser dentro del mundo, como un modo de ser dentro de la libertad de los hombres. Así se crea la alteridad, siempre presupuesta, que confiere una significación específica, a saber, admitir que el otro no está condenado a ser extraño, sino que puede convertirse en mi semejante, en alguien que, como yo, también dice yo. ${ }^{100}$

\section{El sí CONTRA LA ALTERIDAD}

El filósofo de la alteridad es precisamente E. Levinas con quien ya había proyectado la temática de la identidad a partir de Otro. Sin embargo, en muchos puntos no están de acuerdo con él. ${ }^{101}$ "Sí mismo como otro" está dedicado a:

100 Ibid. pág. 372.

101 Ver Paul Ricoeur, De otro modo, Ed. Anthropos, Barcelona, 1999. Que es precisamente un texto en donde critica directamente la ontología de la alteridad, que hace el autor de De otro modo que ser o más allá de la esencia.

102 Paul Ricoeur, op. cit., 1996, pág. 373. 
un tipo de identidad de lo mismo, a la que se opone polarmente la identidad de lo otro, pero en un plano de radicalidad en el que no puede tenerse en cuenta la distinción que yo propongo entre dos clases de identidad, la del ipse y la del idem... Porque en Levinas la identidad del mismo tiene un proyecto común con una ontología de la totalidad, que mi propia investigación jamás ha asumido, ni siquiera encontrado. ${ }^{102}$

Para nuestro autor la alteridad no es igual a la totalidad, pues su "sí mismo" tiene un impulso hacia el Otro, hacia eso que denomina la exterioridad radical. No es con la totalidad con la que guarda un compromiso, sino que es con "el afuera", con el "sí" autoreflexivo de todas las personas gramaticales, que pueden pregonar sobre ellas mismas este "sí", del sí mismo. La importancia de Sí mismo como otro radica en la diferencia que establece entre las dos ontologías, la del yo de Levinas y Husserl, que se extravían en el otro, el primero como totalidad, el segundo como otro yo, a diferencia de la ontología del sí mismo que radica en que el otro también puede predicarse este autoreflexivo "sí mismo", mientras que el yo se auto contiene y no comprende cómo es que el otro también dice de sí "yo", justo después de que la primera persona lo predique de sí.

La ontología del cara a cara condena a la representación del rostro del Otro; el Otro con su rostro cuando aparece en el campo visual, reclama y me hace rehén de un primer movimiento que me obliga a la acción, pues su rostro no encuentra sus limitantes ahí sino que es palabra, palabra que me invita al habla. El otro me hace responsable es decir, capaz de responder. ${ }^{103}$ La argumentación de Levinas es una y otra vez acusada de hipérbole ${ }^{104}$ llevada al paroxismo. La crítica en contra del judío no se detiene y agrega:

103 Emanuel Levinas, Totalidad e infinito, Ed. Sígueme, Salamanca 1977.

104 Por hipérbole, hay que recalcarlo con fuerza, no debe entenderse una figura de estilo, un tropo literario, sino la práctica sistemática del exceso en la argumentación filosófica. Paul, Ricoeur, Sí mismo como otro, Ed. Siglo XXI, México, 1996 pág. 374 y más adelante agrega, que la hipérbole radica en la exageración de las cosas para obtener o inducir el resultado, tal es la epifanía del Rostro, comparado con el Sinahí. Ver Paul, Ricoeur, De otro modo, pág. X.

105 Paul Ricoeur, Op. Cit. 1996, pág. 376 
a partir de ahí, el lenguaje se hace cada vez más excesivo: obsesión del Otro, persecución por el Otro, y sobre todo sustitución del yo por el Otro. ${ }^{105}$ El sujeto es rehén, y también la ipseidad en su pasividad sin arché de la identidad, es rehén. Esta es la expresión más desorbitada de todas, es preferida en este momento para prevenir el retorno insidioso de la auto afirmación de alguna libertad clandestina... me parece el paroxismo de la hipérbole extrema -incluso escandalosa- y, se debe a que el Otro ya no es aquí el maestro de la justicia... sino el ofensor. ${ }^{106}$

\section{IDENTIDAD NARRATIVA EN LA HERMENÉUTICA DEL SÍ}

Para nuestro autor la naturaleza de la identidad narrativa se revela en la dialéctica entre la ipseidad mismidad, y es ahí donde proyecta el despliegue de la hermenéutica del "sí". Pretende que su hermenéutica sea similar a la construcción del concepto de "conexión de la vida" planteado por Dilthey. Concepto que engloba la relación entre teoría filosófica y acción concreta. Husserl reflexionó en esta misma dirección, planteando lo que denominó "Mundo de la vida". Con esta dialéctica pretende estructurar la conexión entre narración, vida e identidad del personaje. Esta concordancia entre acción y teoría, rastreada desde Aristóteles, la sitúa en el centro de su hermenéutica. ${ }^{107}$ En Aristóteles se encuentra lo que se llama "la disposición de los hechos" característica de la trama que hace que se mantenga la noción de temporalidad e identidad, no sólo de los personajes sino de la historia. Esto P. Ricoeur lo denominará las "concordancias", allí mismo sitúa los eventos que trastocan la trama y que nuestro autor denomina "disonancias". Concordancias y disonancias son los dos elementos que va a poner en juego la hermenéutica del "sí" en busca de una identidad narrativa. La hermenéutica pretende en este punto establecer una forma de unir lo concordante, que es la disposición de los hechos y lo disonante que es lo azaroso de los eventos. Desde aquí se puede apreciar la dirección que pretende seguir, pues resulta claro que se trata de mantener la unidad en la diversidad o lacónicamente dicho, la identidad en la

\footnotetext{
106 Ibid.

107 Aristóteles, El arte poética, versión de García Bacca. Ed. Mexicanos unidos México, 1996
} 
La identidad radica en que la trama se construye de la única manera en que se ha realizado, y ver en ello la obligatoriedad de la identidad. Ricoeur encuentra dentro de esta dinámica la noción de continuidad y permanencia. Con lo que la disolución de las pretensiones de un núcleo sólido, se realiza. Lo que sostiene es que la historia no está construida sino hasta que está terminada. Esto nos recuerda el análisis heideggeriano del ser ahí, ${ }^{11}$ cuya historia solamente se determina en la acción, la proyección es libertad pura. Lo mismo en J. P. Sartre, para quien el sujeto, es un ser que puede diseñarse. ${ }^{112}$ Por ello nuestro autor nos puede decir: la inversión del efecto de contingencia, en efecto de necesidad se produce en el corazón mismo del acontecimiento. ${ }^{113}$ La gracia del acontecimiento radica en frustrar las posibles expectativas de la trama y reducirla a la acción. Sin embargo el horizonte no se cierra del todo, puesto que el personaje sujeto a la acción no está terminado, pues siempre está lo indeterminado, lo sorprendente, las acciones por venir que el lector e incluso el narrador mantienen en condición de espera. Bajo esta teoría de la identidad narrativa se conjugan las posiciones que Locke consideraba contrarias, la identidad y diversidad.

\section{IDENTIDAD NARRATIVA Y ADSCRIPCIÓN}

El personaje en sus diversas caracterizaciones es un paciente, es alguien afectado por las circunstancias y éste es el principio de organización a través del cual adquiere su identidad en la trama. La acción que afecta al personaje es recibida en su calidad de paciente, pero esta no es toda la dimensión del personaje, puesto que también es actor de sus acciones. Acciones que influyen en los demás personajes y que contribuyen en la construcción de la trama; en esa medida es actuante o actante siguiendo a Greimas y no sólo paciente. En ese mismo ángulo de reflexión, podemos situar a M. Bajtín con sus reflexiones sobre la construcción del enunciado discursivo y su análisis de los personajes

\footnotetext{
111 Martín Heidegger, Ser y tiempo, Ed Fce, México, 1980, pág. 65.

112 Jean Paul Sartre, El ser y la nada, Ed. Alianza, México, 1986, pág. 429.

113 Paul Ricoeur, op. cit., 1997, pág. 141.
} 
y la acción que se les imputa. ${ }^{114}$ Esta cualidad de acción que posee el personaje, lo hace entrar en la dinámica interpretativa de la acción, como atribución de un sujeto capaz de incisión, con lo que se desata una búsqueda virtualmente infinita, en el plano de las atribuciones. Se inaugura la semántica en forma de búsqueda, que da comprensión del personaje a través de la identificación de las acciones que se le atribuyen. El relato mismo resuelve cualquier antinomia;

por una parte, confiere al personaje una iniciativa, es decir, el poder de comenzar una serie de acontecimientos, sin que estos acontecimientos constituyan un comienzo absoluto, un comienzo del tiempo, y por otra parte dando al narrador tal poder de determinación del comienzo, el medio y el fin de la acción. ${ }^{1.5}$

Pero esta dinámica la insertamos dentro del mundo de la vida para lograr la conexión entre acción, relato y vida, que nos obliga a decir que ni siquiera el autor puede determinar absolutamente el comienzo por medio de la acción, sino que esta identidad llevada al extremo, lo obliga a ser actor o personaje, esto es, afectado por acciones. El escritor se ve obligado a narrar desde eso que se mantiene involuntario y que también lo constituye; el autor también es un personaje dentro de un relato que lo desborda, un relato contado en primera persona igual que sus personajes hacen de ellos mismos en el interior de la trama, y contado por otros en tercera persona, del mismo modo en que sucede en la trama cuando los demás personajes hablan del primero. La diferencia será la acción, no la atribución de la misma, pues al personaje se le atribuyen acciones del mismo modo que a las personas, incluso éste es uno de los criterios de identificación, al igual que sucede en el mundo de la vida. Con lo que la noción de identidad narrativa tiene presentes las aporías de la adscripción. La síntesis entre concordancia y disonancia, hace que, la contingencia del acontecimiento contribuya a la necesidad en cierto sentido retroactivo de la historia de una vida, con la que se iguala la identidad del personaje. ${ }^{116}$ Ahora

\footnotetext{
114 Mijaíl M. Bajtín, Estética de la creación verbal, Ed. Siglo XXI, México, 2003, pág.282.

115 Paul Ricoeur, op. cit., pág. 146

116 Ibid. pág. 147.
} 
veamos que la persona, entendida como lo hace el psicoanálisis, esto es, como relato, no es una identidad, que se construye independientemente de las experiencias del identificado. La persona se identifica a sí misma, con su narración; con la adscripción que hace de eventos y acciones. Por ello podemos decir que el relato construye la identidad del personaje, que podemos llamar su identidad narrativa...es la identidad de la historia la que hace la identidad del personaje. ${ }^{17}$ Con Robert Musil, la trama juega precisamente con las aporías de la identidad, pero no hace sino señalar más, la íntima relación que existe entre identidad y narración, ya que en El hombre sin atributos la descomposición de la forma narrativa, corre paralela a la pérdida de identidad del personaje. ${ }^{118}$ La pregunta por la pérdida de la identidad es la pregunta por lo que significa dentro de la obra, y Ricoeur se pregunta ¿̇e qué modalidad de identidad es de la que se habla cuando se habla de una pérdida de la identidad? La respuesta es: lo que se pierde en la obra de Musil bajo el término de "atributo" es lo que permite igualar al personaje como su carácter. ${ }^{119}$ Esto es, la identidad ídem es la que se pone en juego, como paridad.

*

\footnotetext{
117 Ibidem.

118 IGid, pág. 149.

119 Paul Ricoeur, Sí mismo como otro, Ed. Siglo XXI, México 1996, pág. 149.
} 